\title{
The Research of Displacement Efficiency for Binary Combination Flooding in Offshore Heterogeneous Reservoirs
}

\author{
Yingjie Liu \\ Petroleum Engineering \\ Northeast Petroleum University \\ Daqing, China \\ E-mail: 965265699@qq.com
}

\author{
Yanfu Pi \\ Key Laboratory of Enhanced Oil and Gas Recovery of \\ Ministry of Education of China \\ Northeast Petroleum University \\ Daqing, China \\ E-mail: piyanfu@163.com
}

\begin{abstract}
Aim at the reservoirs condition of high porosity, high permeability, high viscosity of crude oil in the offshore oilfield, this paper used two-dimensional heterogeneous physical model to conduct laboratory displacement experiments which contain water flooding, polymer flooding and binary combination flooding for offshore heterogeneous reservoirs, studied the displacement efficiency of the binary combination flooding after polymer flooding in offshore oilfield. The experiment results showed that final recovery efficiency of binary combination flooding after polymer flooding was $\mathbf{6 4 . 9 8 \%}$ which is higher $\mathbf{3 1 . 8 5 \%}$ than water flooding and higher $19.74 \%$ than polymer flooding; analyzed the distribution diagram of saturation at every stage, the swept efficiency of every layer respectively is $97.89 \%, 94.58 \%, 86.45 \%$, and the oil saturation decreased in the swept area, which turned out that binary combination flooding could not only enlarge the swept volume, but also could enhance the displacement efficiency and the main effect is in low permeability layer.
\end{abstract}

Keywords-oil saturation; binary combination flooding; displacement efficiency; sweep efficiency; recovery displacement.

\section{INTRODUCTION}

The practices of combination in onshore [1-3] show that binary combination flooding which is composed by polymer and surfactant not only could enlarge sweep efficiency but also could enhance displacement efficiency, which is a kind of effective way to further improve oil recovery after polymer flooding at present [4-6]. Xinmin Zhang and others [7] have already ensured the binary multisystem for Suizhong 36-1 block in Bohai oilfield, this system is made up by Hydrophobic associated polymer and Gemini surfactant. Hydrophobic associated polymer can enlarge the sweep volume of injected water, which has been applied successfully in Bohai oilfield [8]; Gemini surfactant in binary multisystem has high surface activity, very low Krafft point and well water solubility, it can show up better efficiency in the aspect of reducing oil-water interfacial tension and can decrease the adverse effect to the viscosity of binary multisystem effectively [9].
Because the displacement efficiency of the binary combination flooding mainly reflects in sweep efficiency and displacement efficiency, this paper has analyzed the change of sweep efficiency and displacement efficiency before and after the binary combination flooding, quantized the contribution of every layer to enhanced oil recovery, and studied research of displacement efficiency for binary combination flooding in offshore heterogeneous reservoirs.

\section{THE BASIS OF EXPERIMENT}

\section{A. Model Design}

The physical model design is the premise of laboratory experiment, this paper has designed two-dimensional heterogeneous physical model as shown as Fig.1, and the geometry of model is $300 \mathrm{~mm} \times 300 \mathrm{~mm} \times 45 \mathrm{~mm}$, is made up by three thickness layer (the permeability respectively is $500 \times 10^{-3} \mu^{2}, 2500 \times 10^{-3} \mu \mathrm{m}^{2}, 4500 \times 10^{-3} \mu \mathrm{m}^{2}$ ), simulates sedimentary formation of positive rhythm. The test points of saturation are laid in the model, and electrode spacing is $10 \mathrm{~mm}$, the distribution of remaining oil can be acquired by the distribution of oil saturation in the model which can be monitored by experiment.

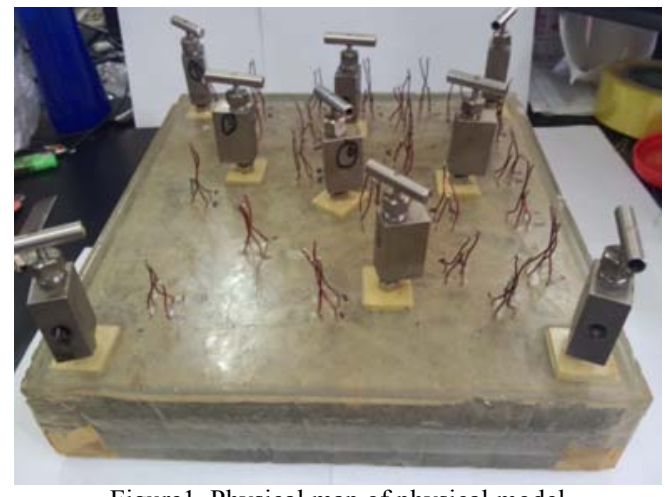

Figure1. Physical map of physical model

B. The Test of Relationship Curve Between Resistance and Oil Saturation

Experimental oil is simulated oil which is mixed by dehydrated crude of offshore oilfoeld and kerosene, whose 
viscosity is $70 \mathrm{mPa} \cdot \mathrm{s}$ when the temperature is $65^{\circ} \mathrm{C}$. Experimental water is made up by saline water artificially, whose degree of mineralization is $9374.13 \mathrm{mg} / \mathrm{L}$. Experimental temperature is $65^{\circ} \mathrm{C}$. The experiments use the core whose geometry is $45 \mathrm{~mm} \times 45 \mathrm{~mm} \times 45 \mathrm{~mm}$ to conduct the test, calculate the quality change of the core before and after experiment, use (1) to calculate the oil saturation of the core, record resistance value, and obtain a series of corresponding data between resistance and oil saturation [10].

$$
S_{o}=\frac{W-W^{\prime}}{\rho_{w}-\rho_{o}} \cdot \frac{1}{V_{1}}
$$

Among the above, $\mathrm{S}_{\mathrm{o}}$ represents oil saturation, $\mathrm{W}$, represents the weight of core saturated water, W' represents the weight of core when the experiment is stable, $\rho_{\mathrm{o}}$ represents the density of crude oil, $\rho_{\mathrm{w}}$ represents the density of formation water, $\mathrm{V}_{1}$ represents the volume of the saturated water.

The relationship curve between resistance and oil saturation is draw according to the corresponding data between resistance and oil saturation, as shown as Fig. 2.

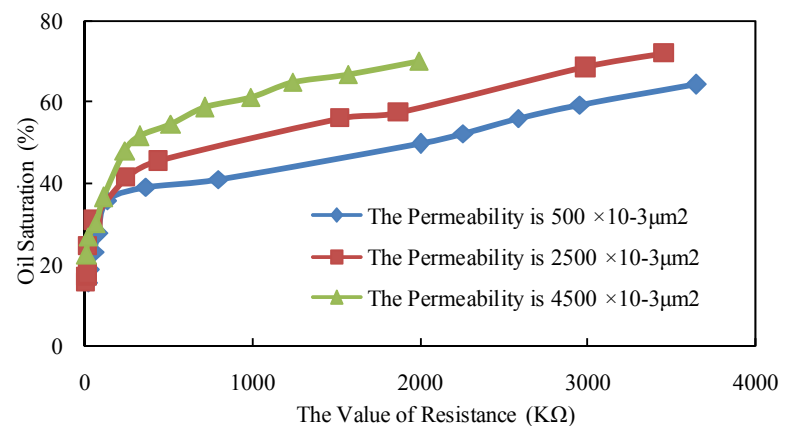

Figure 2.The relationship curve between the resistance and oil saturation under the condition of different permeability

\section{THE SECTION OF EXPERIMENT}

\section{A. Experiment Conditions}

The experimental core is two-dimensional heterogeneous physical model, chemical agents contain hydrophobic associated polymer called HNT300 and surfactant called BHF-4 which is mixed by polyoxyethylene octylphenol ether called TX100 and sulfonate Gemini surfactant, and other conditions are the same as the experiment of the relationship curve between resistance and oil saturation.

\section{B. Experiment Schemes}

The experimental schemes are as shown as TABLE I .

TABLE I . EXPERIMENT SCHEMES

\begin{tabular}{|c|c|c|c|c|}
\hline Schemes & $\begin{array}{l}\text { Water } \\
\text { Flooding }\end{array}$ & $\begin{array}{l}\text { Polymer } \\
\text { Flooding } \\
(\text { o.3PV })\end{array}$ & $\begin{array}{c}\text { Binary } \\
\text { Combination } \\
\text { Flooding } \\
(0.3 \text { PV }) \\
\end{array}$ & $\begin{array}{l}\text { Further } \\
\text { Water } \\
\text { Flooding }\end{array}$ \\
\hline 1 & $\begin{array}{c}\text { To the } \\
\text { water cut is } \\
95 \%\end{array}$ & - & - & - \\
\hline 2 & \multirow{2}{*}{$\begin{array}{c}\text { To the } \\
\text { water cut is } \\
70 \%\end{array}$} & $2000 \mathrm{mg} / \mathrm{L}$ & - & \multirow[b]{2}{*}{$\begin{array}{c}\text { To the } \\
\text { water cu } \\
\text { is } 95 \%\end{array}$} \\
\hline 3 & & $2000 \mathrm{mg} / \mathrm{L}$ & $\begin{array}{c}1750 \mathrm{mg} / \mathrm{L} \mathrm{HNT}- \\
300+0.2 \% \mathrm{BHF}- \\
4\end{array}$ & \\
\hline
\end{tabular}

\section{Experiment Procedures}

Prepare simulation formation water and simulation oil for offshore oilfield; Evacute artifical core and then saturate simulation formation water, record the weight of saturated water, calculate the porosity of core; Use the satutarion method of constant voltage to conduct saturating oil, record the weight of saturated oil, calculate the initial oil saturation of the core; Conduct displacement experiment according to the specific experiment scheme, record liquid producing capacity, water production, pressure, and acquire the value of resistance.

\section{Experiment Results and Analysis}

The template is used to format your paper and style the text. All margins, column widths, line spaces, and text fonts are prescribed; please do not alter them. You may note peculiarities. For example, the head margin in this template measures proportionately more than is customary. This measurement and others are deliberate, using specifications that anticipate your paper as one part of the entire proceedings, and not as an independent document. Please do not revise any of the current designations.

1) Experiment results

The recovery curves of the three kinds of schemes are as shown as Fig. 3.

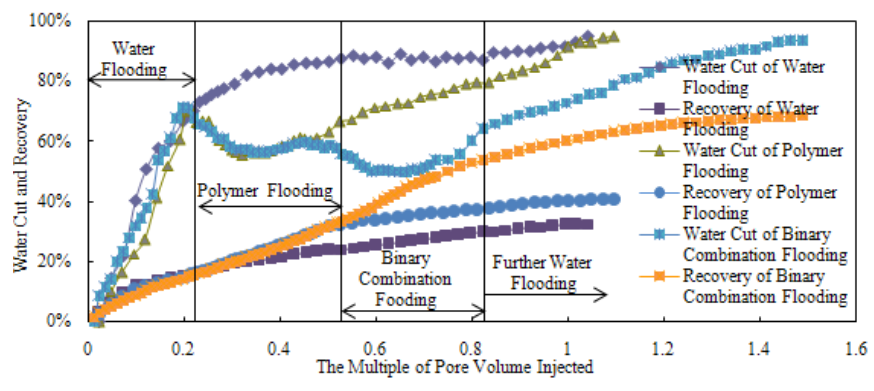

Figure 3.Recovery curves for the three kinds of experiment schemes

It can be seen from Fig. 3 that the water cut of the model decreases after injecting polymer, which shows that the polymer has had an effect; the displacement efficiency of the binary combination flooding for two-dimensional heterogeneous physical model is remarkable, the ultimate recovery factor is $64.98 \%$ which has increased by $19.74 \%$ than polymer flooding and has increased by $31.85 \%$ than water flooding.

2) The contribution of every layer to enhanced oil recovery

The results are as shown as TABLE II. 
TABLE II CONTRIBUTION VALUES TO ENHANCED THE OIL RECOVERY FOR EACH THICK LAYER IN THE DIFFERENT STAGES

\begin{tabular}{|c|c|c|}
\hline \multirow{2}{*}{ Layers } & \multicolumn{2}{|c|}{$\begin{array}{c}\text { The Contribution of Every Layer } \\
\text { to Enhanced Oil Recovery }\end{array}$} \\
\cline { 2 - 3 } & $\begin{array}{c}\text { Polymer flooding to } \\
\text { water flooding (\%) }\end{array}$ & $\begin{array}{c}\text { Binary combination } \\
\text { Flooding to } \\
\text { polymer flooding } \\
\text { (\%) }\end{array}$ \\
\hline $\begin{array}{c}\text { High } \\
\text { permeability } \\
\text { layer }\end{array}$ & 50.97 & 16.58 \\
\hline $\begin{array}{c}\text { Middle } \\
\text { permeability } \\
\text { layer }\end{array}$ & 33.77 & 35.83 \\
\hline $\begin{array}{c}\text { Low } \\
\text { permeability } \\
\text { layer }\end{array}$ & 15.26 & 47.59 \\
\hline
\end{tabular}

It can be seen from TABLE II that the contribution of high permeability layer to enhanced oil recovery after polymer flooding is $50.97 \%$ which is the biggest, the middle permeability layer's is $33.77 \%$ which takes the second place, the others' is from low permeability layer. Combining with Fig. 4, there has formed the mainstream channels in high permeability layer during water flooding stage as shown as Fig. 4-a, the polymer flooding mainly enlarges the sweep volume of high and middle permeability layer and then employs remaining oil in the two layers, but the oil saturation of middle permeability layer is higher as shown as Fig. 4-b and the sweep volume of low permeability layer is smaller as shown as Fig. 4-c , so the middle and low permeability layers are the mainly potential layers after polymer flooding; The contribution of low permeability layer to enhanced oil recovery after binary combination flooding is $47.59 \%$ which is the biggest, the middle permeability layer's is $35.83 \%$ which takes the second place, the high permeability layer's is $16.58 \%$, the above shows that the binary combination flooding mainly has played an effect on low permeability layer and has displaced the remaining oil in low permeability layer.

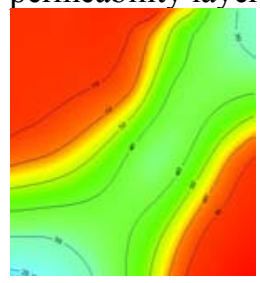

Water flooding Figure 4-a. The distribution graph of oil saturation for high permeability layer under the different displacement schemes

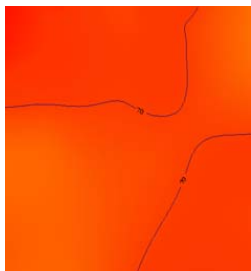

Water flooding
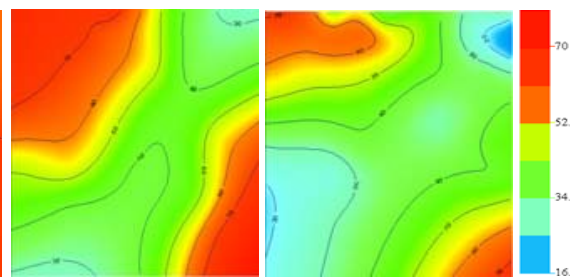

Polymer flooding Binary combination flooding Figure 4-b. The distribution graph of oil saturation for middle permeability layer under the different displacement schemes

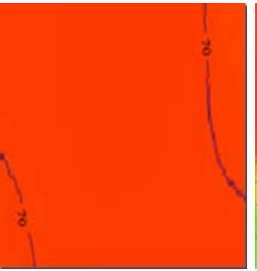

Water flooding

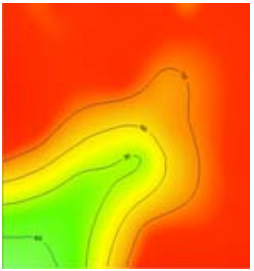

Polymer flooding Binary combination flooding
Figure 4-c. The distribution graph of oil Saturation for low permeability layer under the different displacement schemes

3) The changes of sweep efficiency and displacement efficiency for every layer in different schemes

Because of the adverse mobility ratio between injected water and heavy oil at the stage of water flooding, the injected water mainly flows along high permeability layer, the situation of swept is worse, the effect of anisotropism of reservoir is serious; the sweep efficiency of every layer after polymer flooding respectively is $92.75 \%, 76.19 \%$, $45.64 \%$, the injection of polymer has adjusted the anisotropism of reservoir and enlarged the sweep volume of middle and high permeability layer; the sweep efficiency of every layer after binary combination flooding respectively is $97.89 \%, 94.58 \%, 86.45 \%$, the remaining oil has been employed widely and the oil saturation has decreased obviously in middle and low permeability layer, that shows the synergistic effect between previous injected polymer and binary multisystem has expanded the sweep volume of middle and low permeability layers in the model, and the oil saturation of every layers in the swept areas decreases during the injection process of binary multisystem, which has increased displacement efficiency substantially, the above shows that binary multisystem can also enhance displacement efficiency when it is enlarging sweep volume.

By the way of laying monitoring point of electrodes, comparing the experiment results of binary combination flooding, polymer flooding and water flooding for fourlayer heterogeneous thicken model, it can be seen that the effect of enhanced oil recovery for polymer flooding is worse. Compared with polymer flooding, the injection pressure of binary multisystem is bigger, it has given full play to the effect of tackifying of injected polymer and improving mobility ratio, superadding the effect of enlarging sweep volume for binary multisystem, the sweep volume of model has increased remarkably, at the same time the binary combination flooding can further decrease the interfacial tension and enhance the displacement efficiency for every layers, thus it can further enhance the oil recovery than polymer flooding.

\section{CONCLUSIONS}

1. The contribution of low permeability layer to enhanced oil recovery after binary combination flooding is $47.59 \%$ which is the biggest, the middle permeability layer's takes the second place which is $35.83 \%$, and the high permeability layer's is $16.58 \%$, the main effect of binary combination flooding is in the low permeability layer, and has displaced the remaining oil in the low permeability layer by a large margin.

2. The displacement efficiency of binary combination flooding after polymer flooding is remarkable and its 
ultimate recovery factor is $64.98 \%$ which has increased by $19.26 \%$ than polymer flooding. The synergistic effect between previous injected polymer and binary multisystem has expanded the sweep volume of middle and low permeability layers in the model, and the oil saturation of every layer in the swept areas decreases, which has increased displacement efficiency substantially; binary multisystem can also enhance displacement efficiency when it is enlarging sweep volume.

\section{ACKNOWLEDGMENT}

The research work was joint funding between the national major projects "Reservoir Research for Enhanced Oil Recovery Technology after Polymer Flooding in Offshore Oilfields" (2011ZX05024-004-14).

\section{REFERENCES}

[1] Demin Wang, Heng Liu, Jingang Niu and Fuming Chen. "Application Results and Understanding of Several Problems of Industrial Scale Polymer Flooding in Daqing Oil Field,"SPE 50928, 1998, pp. 477-481.

[2] Zhenhua Zhang, Jiecheng Cheng and Lin Li. "The Pilot Test Technology of Polymer Flooding," Beijing: Petroleum Industry Press, 1996.

[3] Li Liu. "The Distribution and Measures for Potential Exploitation of Remaining oil After Polymer Flooding," Daqing: Daqing Petroleum Institute, 2005.

[4] Peihui Han, Qun Zhao, Shuangshu Mu, Zhiping Li and Hasi Bateer. "The Research of The Method of Further Enhanced Oil Recovery
After Polymer Flooding," Daqing Petroleum Geology and Development,vol.25,Oct.2006, pp.81-84, DOI:10.3969/j.issn.10003754.2006.05.023

[5] Wenxiang $\mathrm{Wu}$, Yufeng Zhang, Jiqiang $\mathrm{Hu}$ and Deqi Xing. "Physical Simulation Experiment of Binary Compound System of Polymer and Surfactant," Journal of Daqing Petroleum Institute, vol.29,Dec.2005,pp.98-100,DOI:10.3969/j.issn.20954107.2005.06.031

[6] Yongheng Gang, Hui He, Li Hu and Guojun Li. "The Technology Development Review of Enhanced Oil Recovery for Binary Combination Flooding," Oil-Gasfield Surface Engineering, vol.12, Dec.2010, pp.61-62, DOI:10.3969/j.issn.1006-6896.2010.12.030.

[7] Xinmin Zhang, Yongjun Guo, Rusen Feng, Jianxin Liu, Jian Zhang and Xin Lv. "The Performance Study of Binary Compound System Which Suits for Suizhong 361 Reservoir in Bohai Oilfield," China Offshore Oil and Gas, vol.29, Sep.2007, pp. 30 - 34.

[8] Shouwei Zhou, Ming Han, Wentao Xiang, Jian Zhang, Wei Zhou and Wei Jiang. "The Technology Research and Application of Enhanced Oil Recovery with Polymer Flooding in Bohai Oilfield," China Offshore Oil and Gas, vol.18, Dec.2006, pp.386 - 389, DOI:10.3969/j.issn.1673-1506.2006.06.006.

[9] Yuexing Wang, Dong Han, Hongzhuang Wang, and Yiqiang Lu. "Adsorption, Auto-agglutination and Characters for Gemini Surfactant," Chemistry World, vol.4, 2003, pp.216-219, DOI:10.3969/j.issn.0367-6358.2003.04.015.

[10] Chunmei Yang, Hongqi Li, Dawei Lu, Fangli Zhang, Yuan Gao and Yingchao Shao. "The Relationship between Electrical Resistance and Saturability for Rocks in The Different Displacement Ways," Journal of Jilin University: Earth Science Edition, vol.35, Sep.2005, pp.667-671, DOI:10.3969/j.issn.16715888.2005.05.021. 